\title{
Conceptual equivalence of items and semantic equivalence of the Brazilian version of the EORTC QLQ-ELD14 instrument to evaluate the quality of life of elderly people with cancer
}

Bianca Maria Oliveira Luvisaro ${ }^{1}$ Josiane Roberta de Menezes'

Claudia Fernandes Rodrigues ${ }^{1}$ Ana Luiza Alfaya Gallego Soares² Camila Drumond Muzi ${ }^{1}$ Raphael Mendonça Guimarães ${ }^{3}$

Abstract

Objective: to describe the process of semantic equivalence, the first stage in the validation of the EORTC QLQ-ELD14 instrument for Brazilian Portuguese. Method: Direct and independent translations of the instrument into Portuguese were carried out and validated by a meeting of experts to generate a synthesis version. The version chosen was submitted to reverse translations into English, and the form was pre-tested with patients. At the conclusion of the process, a summary version was presented. The pre-test and the final version of the instrument were applied to a total of 28 patients at a high complexity oncology treatment center. Result: after completion of the first round of pretesting, some adjustments for the next phase of the study were necessary by the expert committee. After these adjustments, in the second phase of pre-testing, the instrument was wellaccepted by the population. Conclusion: the Portuguese summary version of the EORTC QLQ-ELD14 instrument for assessing the quality of life of elderly cancer patients is ready to be submitted to the next stages of the evaluation of its psychometric properties.

Keywords: Aged. Neoplasms. Quality of Life. CrossCultural Comparison.

Instituto Nacional de Câncer José de Alencar, Coordenação de Ensino e Divulgação Científica. Rio de Janeiro, RJ, Brasil.

2 Universidade Federal do Rio de Janeiro, Instituto de Estudos em Saúde Coletiva. Rio de Janeiro, RJ, Brasil.

3 Fundação Oswaldo Cruz, Escola Politécnica de Saúde Joaquim Venâncio, Laboratório de Educação Profissional em Vigilância em Saúde. Rio de Janeiro, RJ, Brasil. 


\section{INTRODUCTION}

Cancer is a worldwide health care problem. According to Globocan 2012, part of the International Agency for Cancer Research, there were 14.1 million newly diagnosed cancer cases and 8.2 million deaths due to cancer around the world in $2012^{1}$.

In Brazil, cancer-related problems constitute a pressing health issue. Approximately 596,000 new cancer cases are estimated to occur in 2016, with similar estimates for $2017^{2}$.

In recent decades, population ageing has had a significant role in the progressive increase of cancer prevalence in Brazil and around the world. The World Health Organization (WHO) estimates the annual global cancer burden will rise to no fewer than 21.4 million new cases in 2030. In low and medium-income countries, more than half of those who die due to cancer are aged 70 or older $^{2,3}$.

The stigma of having cancer and the condition of being older contribute to the complexity of care in this population. There are specific psychological, social and biological needs that need to be properly addressed among older people 4 . As social, health and well-being aspects are different among older adults, there is a need to employ instruments specifically designed to evaluate the quality of life of this population ${ }^{5,6}$. Thus, there is increasing agreement about the importance of cooperation between geriatrics and oncology, not due to the increasing incidence of cancer among older people but also due to the need to explore modifications in oncological treatment as a result of the physiological changes in this age group ${ }^{7}$.

The importance of evaluating health-related quality of life has been increasingly acknowledged in health care contexts. Quality of life, as defined by the WHOQOL Group, is the "individual's perception of their position in life in the context of the culture and value systems in which they live and in relation to their goals, expectations, standards and concerns". Such definition makes quality of life a broad concept, affected by physical and psychological health, level of independence, social relations, individual beliefs and relationship to the environment.
A number of issues, such as progressive weakness and consumption, the inability to autonomously perform daily activities, stress, ageing and the possibility of death, together significantly impair quality of life among cancer patients?

EORTC QLQ-C30 is a widely used and internationally validated instrument designed to evaluate the quality of life of cancer patients, with complementary modules that allow improved evaluation of specific situations ${ }^{10-12}$. EORTC QLQ-EL14 is one such module, and was recently developed in pursuit of the evaluation of the quality of life of cancer patients over the age of 70 years. It has not yet been validated for use in Brazil ${ }^{13}$.

As few Brazilian studies have supported or used questionnaires that permit the evaluation of different aspects of the lives of patients with chronic-degenerative diseases, the translation, cross-cultural adaptation and posterior validation of instruments that assess quality of life in older people is of great importance. Adapting and validating the EORTC QLQ-ELD14 for use in Brazil will ensure new resources in data collection and analysis when evaluating the effectiveness of therapeutic procedures in the promotion of the quality of life in this age group, in addition to potentially revealing areas where further scientific investigation is required.

The present study therefore aims to perform the first step in the cross-cultural adaptation of the Brazilian version of EORTC QLQ-ELD14.

\section{METHODS}

This study describes the development of the Brazilian version of the EORTC QLQ-ELD14. To this end, convenience sample of 28 patients, with a mean age of 68 years, was selected. It should be noted that the sample group was selected, at each pretest stage, in order to identify a pattern of response or difficulty in understanding the questionnaire. Therefore, as this is a study whose central element is internal validity, there was no need to perform a sample size calculation. From this assumption, the sample was then selected to include clinical and surgical and palliative and non-palliative patients, and 
the process was conducted by theoretical saturation, according to which data collection was interrupted when it was found that no new theoretical elements arose that changed or generated corrections in the version of the instrument ${ }^{13}$.

The Brazilian version of the EORTC QLQELD1 $14^{14}$ is the result of a cross-cultural adaptation process performed in agreement with the procedures recommended by the EORTC Quality of Life Group. The process to ensure semantic and conceptual equivalence follows the Herdman universalist approach ${ }^{15}$, which was introduced in Brazil by Reichenheim ${ }^{16}$. This study was authorized by the authors via electronic communication (e-mail) in February 2014.

As part of the process of conceptual and item equivalence, a broad literature review was performed. This included the concepts on which the formulation of the original instrument was based, and the applicability of these in a Brazilian context. Next, an expert committee was formed with an epidemiologist, four nurses with oncological expertise and a psychiatrist. The committee evaluated the adequacy of the discussed concepts and of the items that formed the questionnaire.

The original questionnaire was translated into Portuguese independently by a physician and a biomedicine professional; both were English native speakers and fluent in Portuguese. Each of these translations (T1 and T2) were backtranslated by two other independent translators, one physician and one professional translator, both native Portuguese speakers, fluent in English and with ample knowledge of health care vocabulary. These back-translations were coded R1 and R2.

EORTC QLQ-ELD14 is composed of 14 items distributed into five subscales, which evaluate mobility, worries about the future, worries about others, maintaining purpose and the burden of disease domains - and two individual items, which assess joint stiffness and family support. The format is a Likert scale with four response options for all items ${ }^{13}$.
The ample experience of the members of the expert committee in oncology and their proficiency in English were used in the formal evaluation of the two previously mentioned back translations, which was performed by comparing the two versions and by comparing both of these with the original instrument. The decision of the committee was to evaluate referential meaning $(\mathrm{R})$ using scores of 0 to $100 \%$ in each question. Regarding general meaning $(\mathrm{G})$, the decision was to rank each question in one of four categories: unaltered (UN), little altered (LA), much altered (MA) and completely altered (CA).

The committee evaluated the adequacy of structural modifications in some questions, in order to simplify phrasing and facilitate comprehension. All issues were exhaustively debated with the aim of achieving consensus. After all the alterations were made, the preliminary version was formulated and tested. During the first pre-test, the collection of results was by self-completion; during the second, an interview technique was adopted.

It is worth mentioning that the participants possessed clinical conditions that allowed them to respond adequately to the questions. This condition was evaluated based on the characteristics described by the Karnofsky Performance Index. Patients were interviewed at the time of initial hospitalization, so that hospitalization time could not be considered as a selection bias factor.

Testing was performed in two rounds of pretesting in a convenience sample of 28 inpatients in a high-complexity oncology center in Rio de Janeiro. The pre-testing rounds were the foundation for further evaluation of recruitment strategies, scale structure and item comprehension assessment (Figure 1).

This study was approved by the Research Ethics Committee of the José Alencar Gomes da Silva National Cancer Institute and the approval number was 863.339. All respondents freely agreed to participate and signed an Informed Consent Form. All were approached on a timely basis in a manner that would not result in embarrassment in front of family members or other patients, and at a moment when they were not being submitted to any test or evaluation. 


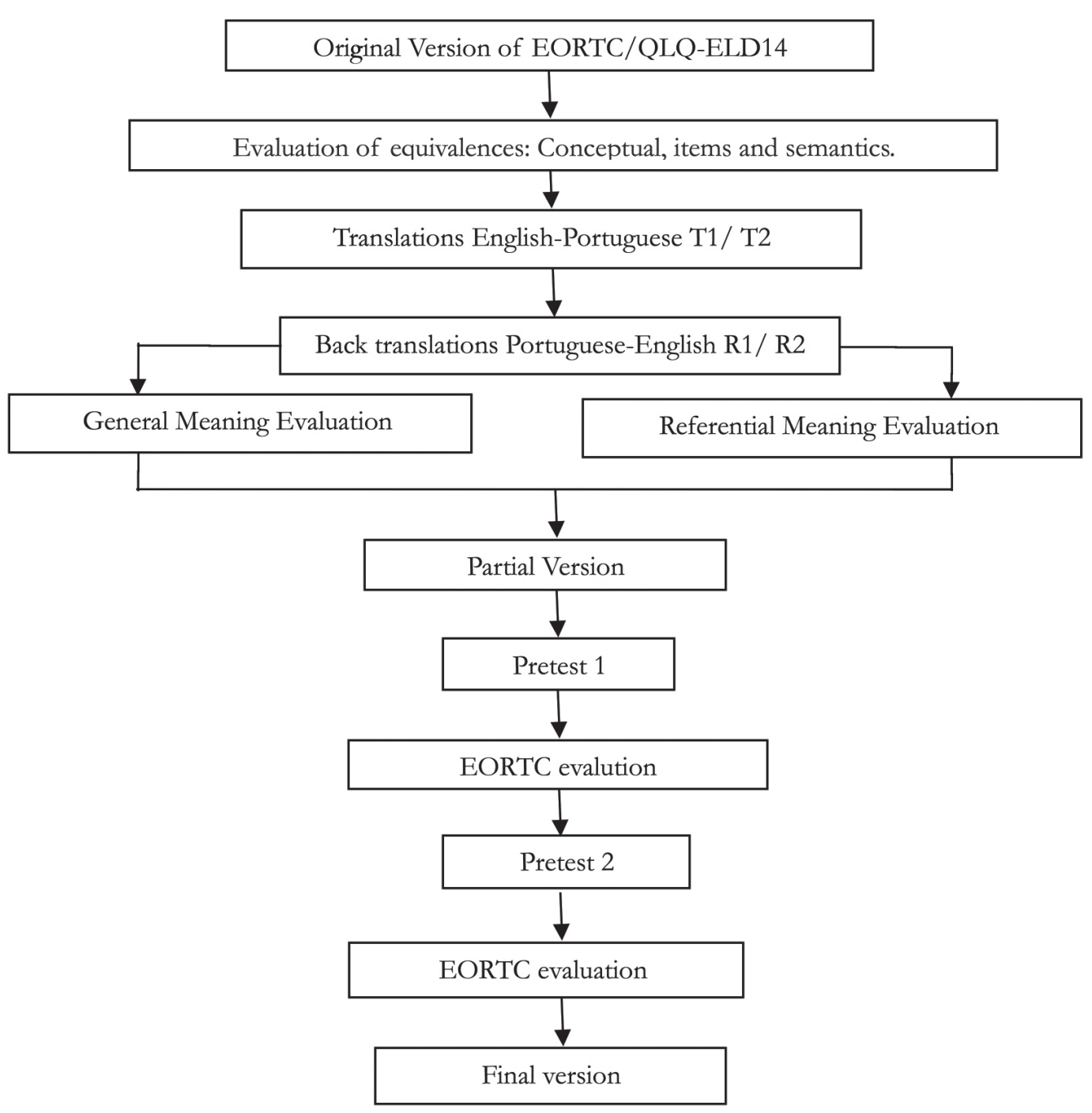

Figure 1. Stages of semantic equivalence of EORTC ELD 14 instrument for Brazilian Portuguese Rio de Janeiro, RJ, 2016.

\section{RESULTS}

Semantic equivalence evaluation is expressed from the results of two back translations and the respective general and referential meanings, as well as those of the original instrument (table 1).

In general, there was appropriate equivalence when the items of the two back-translations were compared with the original items. In most of the items, the referential meaning score was between 90 and $100 \%$. The most striking dissimilarities between R1 and R2 were noted in item 10, where the referential meaning score in R1 was $60 \%$, and it was found that there was a major change in item meaning. The remaining items had good equivalence regarding general and referential meaning.

Table 2 shows the original items, the T1 and T2 translations into Portuguese and the preliminary Portuguese version. The expert committee analyzed the $\mathrm{T} 1$ and $\mathrm{T} 2$ versions and chose the one that was easier to understand and more accurately expressed the meaning of the original item. Alterations in the formulation of the preliminary version consisted in verb tense changes only. Items were re-written in the past simple, as opposed to the present perfect, in order to emphasize the time frame, which was the week before answering the questionnaire. 


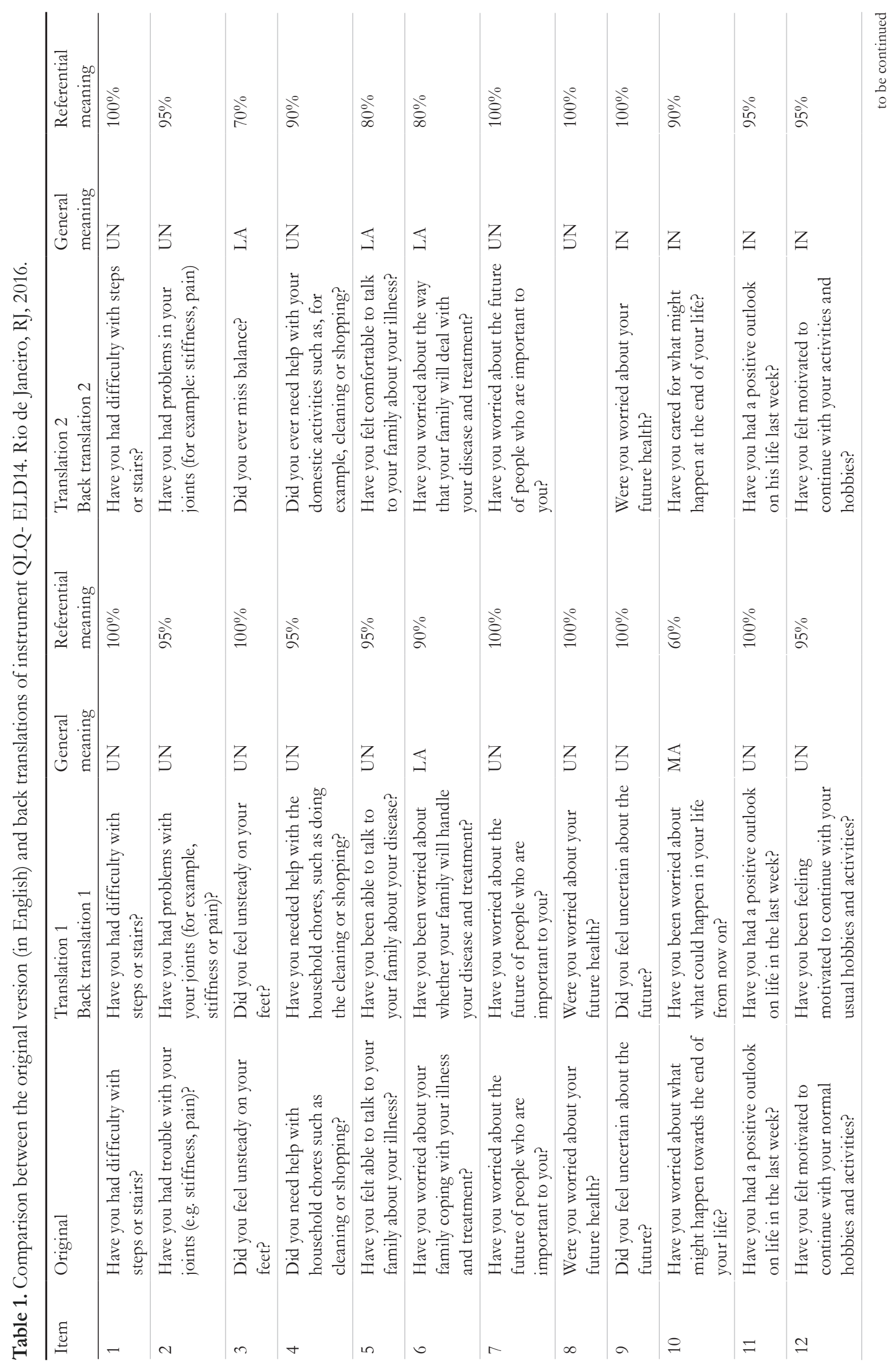




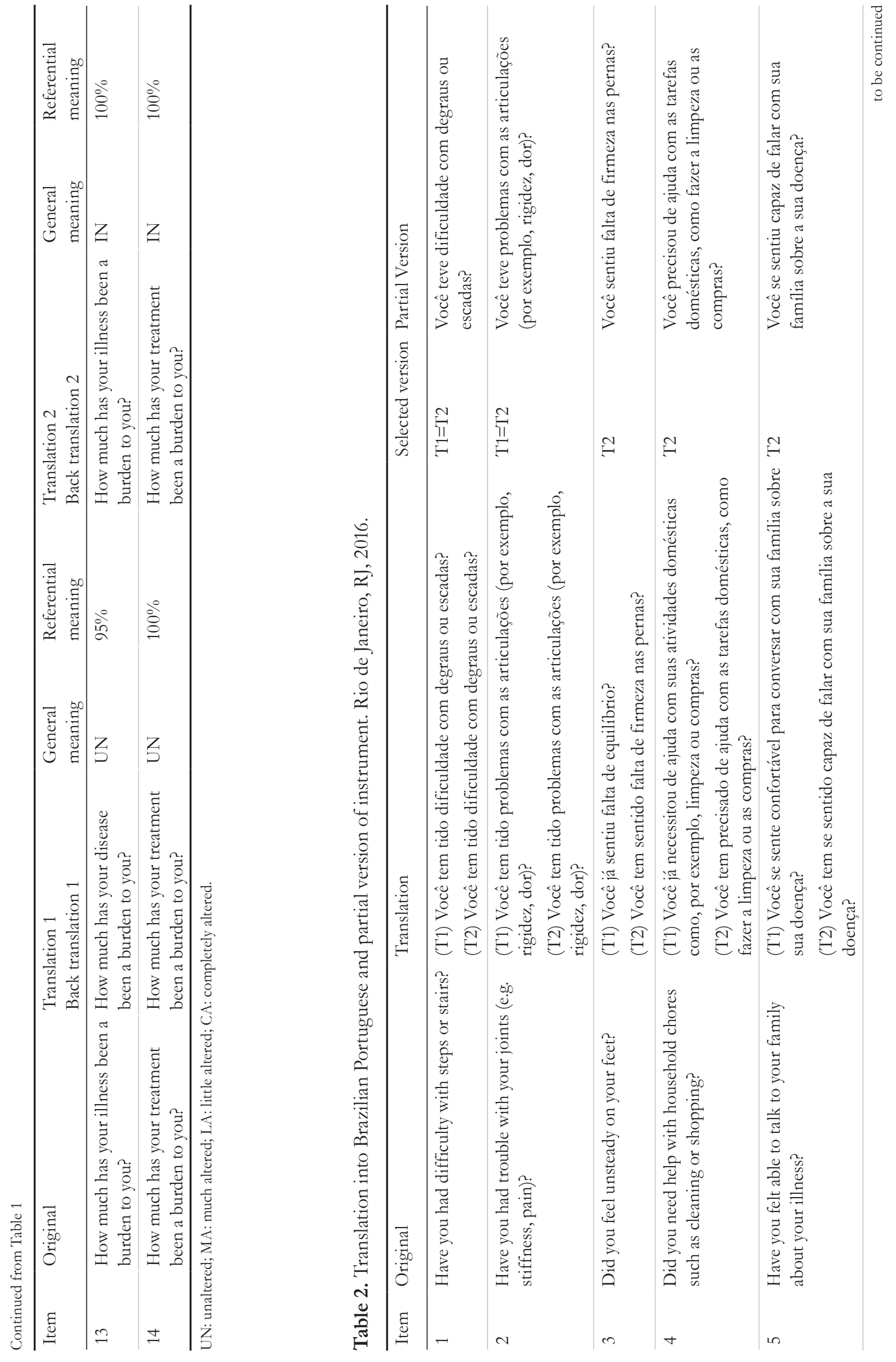




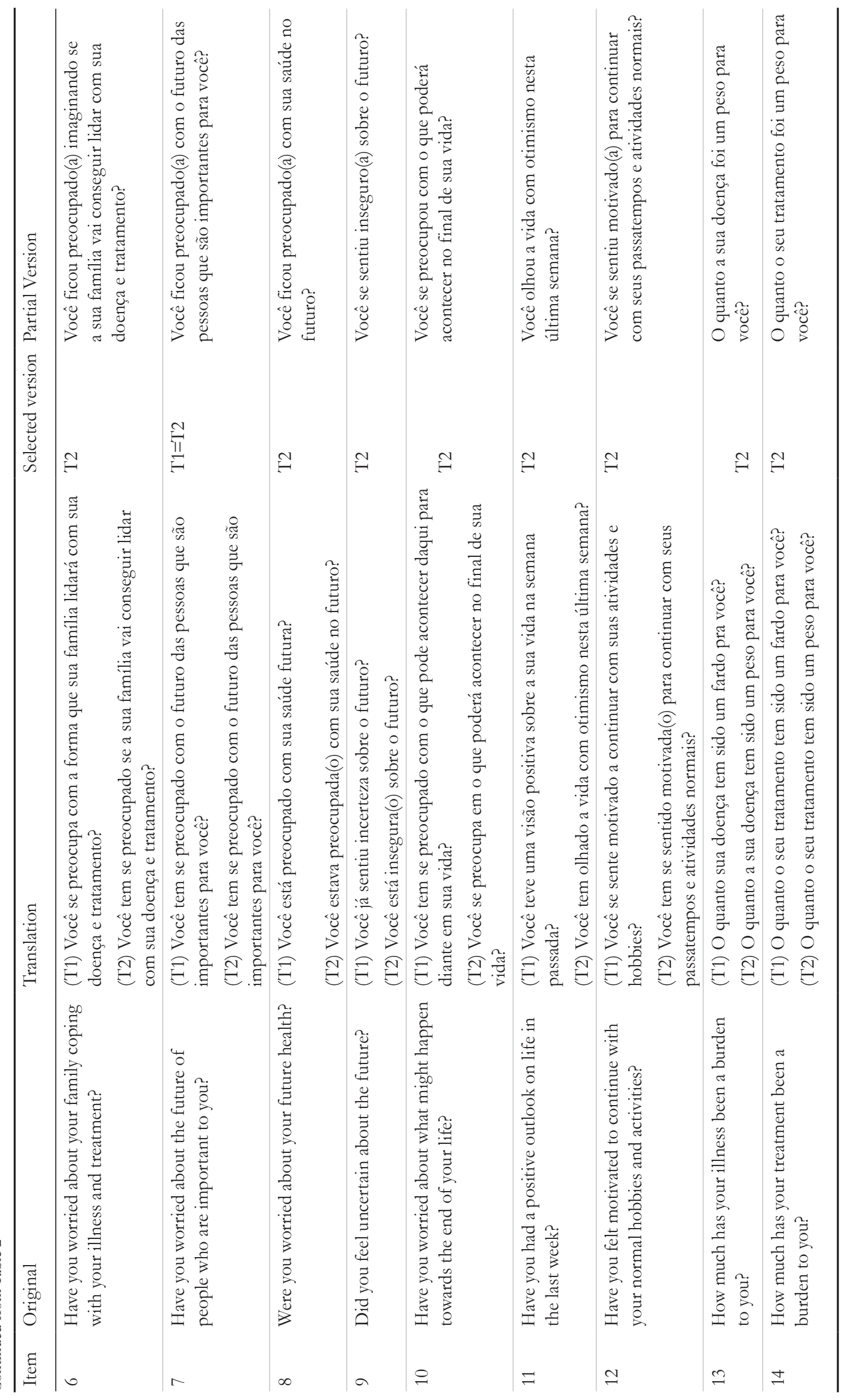


In the first round of pre-testing, 12 patients answered the questionnaire, with the aim of evaluating general aspects regarding acceptance by the target population, difficulties in patient recruitment and phrasing comprehension.

Firstly, we asked the patients to complete the questionnaire by themselves, with no help from family members or friends. The mean questionnaire completion time was 5 minutes and 34 seconds in the first round of pre-testing. Most respondents were female $(58.3 \%)$. Regarding educational level, $33.3 \%$ had less than eight years of primary education, $25 \%$ had completed primary education only, $16.6 \%$ had completed secondary education; and $16.6 \%$ had no schooling. Oncological treatment intent was palliative in $58.33 \%$ of cases and curative among $41.66 \%$ of individuals.

In the original questionnaire, there are two sentences with instructions to respondents, which were translated literally. The third sentence was about circling the best option in each item, and was omitted since it did not apply to the interview format used to fill the questionnaire (differing from the initial recommendation of the EORTC). This decision was made as, during pilot testing, it was observed that it was very difficult for respondents with less schooling and/or visual or writing issues to complete the questionnaire by themselves.

It should be noted that, in the beginning, the general ease of understanding of some items was impaired, requiring the paraphrasing and explanation of each item of the partial version.

In the first round of pre-testing there were serious issues in comprehension in most (11) of the items, with items 2 and 4 the most troublesome.

In item 1, to have "difficulty" with steps and stairs was not clearly understood and explanation about the difficulty being related to climbing steps or stairs was required. This was altered before the second round of pre-testing.

In item 2, less literate patients had difficulties understanding the word "joint" (in Portuguese, "articulação"), even after using synonyms, and in some cases, even after giving examples. As joint symptoms occur frequently in older people in general we considered that researchers should exercise caution regarding the comprehension of less literate people when using this item.

In item 4 the patient is asked about the need for assistance when doing housework, which was troublesome to those who had been hospitalized for longer periods of time. Additionally, some understood that mobility issues were inevitable during their stay in the hospital and spontaneously answered based on their capacity to perform housework before hospital admission.

The Portuguese version of Item 5 was "did you feel capable of talking to your family about your disease?", but often required explanation, as "Do you feel you could you talk to your family about your disease?". The expert committee altered this to "were you able to talk to your family about your disease?", which was well understood in the second round of pre-testing.

In item 6 there was some difficulty with the word "coping" (in Portuguese, "lidar"), so the expert committee substituted this with "reagir", which is more colloquial and maintained the original meaning of the sentence.

In item 9, we noticed that "uncertain" ("inseguro(a)") was poorly understood among less literate respondents, so the committee changed it to "fear" ("medo").

Item 10 was well understood but some patients became emotional and even worried when thinking about the future. We feel this is an issue of which researchers should be aware.

In item 11, the T2 translation "Did you have an optimistic approach to life recently?" entailed confusion regarding the meaning of the word "optimism", so that explanation was often needed. Thus, the expert committee chose to use the T1 translation, "Did you have a positive outlook on life in the last week?", which was equivalent to the original phrasing of the original item.

In item 12, "hobbies and activities" was substituted with a more colloquial expression, "things that you like to do", aiming at greater comprehension among the respondents. 
In items 13 and 14, "burden" was poorly understood by a minority of less literate participants, apparently due to its abstract connotation. On the other hand, some patients observed that the treatment had indeed been hard, but not to the extent that they felt it was a "burden", which they considered to be applicable only in extreme circumstances. These option for them to express how they felt. In most cases, though, the item was understood, and thus the expression "burden" was maintained.

Items 3, 7 and 8 were easily understood and remained unchanged.

After the first round of pre-testing the expert committee re-revaluated the questionnaire, having made the necessary alterations and changes to the general structure of the scale. The minor changes in

some terms allowed greater objectivity and, a more colloquial style, resulting in greater comprehension and acceptability of the instrument.

We performed a second round of pre-testing with 16 patients to evaluate item comprehension. Table 3 shows the similar characteristics of respondents participating in rounds 1 and 2. One foreign participant was excluded for experiencing difficulty with cultural and conceptual issues. The sample was then reduced to 16 volunteers, with a mean age of 65 years and a mean test answering time of 6 minutes and 13 seconds. This was also a convenience sample, and most participants were female $(62.5 \%)$. As in the first sample a significant number of patients had a level of schooling of below primary (37.5\%) (Table 3 ). Most of the patients were undergoing palliative treatment.

Table 3: Socio-demographic and clinical characteristics between pretest 1 and pretest 2. Rio de Janeiro. RJ. 2016.

\begin{tabular}{|c|c|c|c|}
\hline Variable & $\begin{array}{l}\text { Pretest } 1(\mathrm{n}=12) \\
\text { Mean }(+\mathrm{dp})\end{array}$ & $\begin{array}{l}\text { Pretest } 2(n=16) \\
\text { Mean }(+d p)\end{array}$ & $p$ value ${ }^{*}$ \\
\hline Age & $69.1( \pm 7.96)$ & $65.0( \pm 6.54)$ & 0.47 \\
\hline Interview Duration & $5 \min 01 \mathrm{~s}( \pm 1 \mathrm{~min} 36 \mathrm{~s})$ & $5 \min 15 \mathrm{~s}( \pm 1 \min 43 \mathrm{~s})$ & 0.89 \\
\hline Variable & $\mathrm{N}(\%)$ & $\mathrm{N}(\%)$ & \\
\hline \multicolumn{4}{|l|}{ Sex } \\
\hline Male & $07(58.33)$ & $10(62.5)$ & 0.56 \\
\hline Female & 05 (41.66) & $06(37.5)$ & \\
\hline \multicolumn{4}{|l|}{ Skin color/Ethnicity } \\
\hline White (Caucasian) & $04(33.33)$ & $05(31.25)$ & 0.88 \\
\hline Black (Afro-Brazilian) & $06(50.00)$ & $09(56.25)$ & \\
\hline Yellow (Asian-Brazilian) & $02(16.66)$ & $02(12.5)$ & \\
\hline \multicolumn{4}{|l|}{ Literacy } \\
\hline Illiterate & $02(16.66)$ & $01(6.25)$ & 0.84 \\
\hline Primary School & $07(58.33)$ & $09(56.25)$ & \\
\hline High School & $02(16.66)$ & $03(18.75)$ & \\
\hline Higher education (complete) & $01(8.33)$ & $03(18.75)$ & \\
\hline \multicolumn{4}{|l|}{ Marital Status } \\
\hline Single & $03(25)$ & $04(25)$ & 0.83 \\
\hline Married & $04(33.33)$ & $07(43.75)$ & \\
\hline Widower & $04(33.33)$ & $03(18.75)$ & \\
\hline Divorced & $01(8.33)$ & $02(12.5)$ & \\
\hline \multicolumn{4}{|l|}{ Therapeutics } \\
\hline Curative & $05(41.66)$ & $07(43.75)$ & 0.92 \\
\hline Palliative & $07(58.33)$ & $09(56.25)$ & \\
\hline
\end{tabular}

${ }^{*} p$ value was calculated from Fisher's exact test (categorical variable) and Mann Whitney test (continuous variable) 
In the second round, after the alterations made by the committee, the items were easily understood and the previously noted comprehension issues were resolved, although attention should be paid to items 2 and 4 when applying the questionnaire.

When specifically asked whether any item was offensive or uncomfortable to answer at the end of the interview, all the patients said no. However, it was observed that some were moved by the questions, especially in items about worries about the future, family support and death. Examiners should therefore be attentive and offer appropriate support when needed.

The evaluation performed after the second round of pre-testing was that the instrument was easily understood regarding semantics, the structure was appropriate and that the interview format should be used in the Brazilian population. The final version of the instrument is seen on Table 4.

Table 4: Final version - EORTC QLQ-ELD14. Rio de Janeiro, Brasil, 2016.

Às vezes os pacientes relatam que têm os seguintes sintomas ou problemas. Por favor, indique o quanto cada um desses sintomas ou problemas esteve presente durante a última semana.

\begin{tabular}{|c|c|c|c|c|c|}
\hline Item & Durante a última semana: & Nada & Um pouco & Moderadamente & Muito \\
\hline 1 & $\begin{array}{l}\text { Você teve dificuldade para subir ou descer degraus ou } \\
\text { escadas? }\end{array}$ & 1 & 2 & 3 & 4 \\
\hline 2 & $\begin{array}{l}\text { Você teve problemas nas articulações/dobras/juntas, } \\
\text { por exemplo, dificuldade em mexer ou dor? }\end{array}$ & 1 & 2 & 3 & 4 \\
\hline 3 & Você sentiu falta de firmeza nas pernas? & 1 & 2 & 3 & 4 \\
\hline 4 & $\begin{array}{l}\text { Você precisa de ajuda com as tarefas domésticas, } \\
\text { como fazer a limpeza ou as compras? }\end{array}$ & 1 & 2 & 3 & 4 \\
\hline 5 & $\begin{array}{l}\text { Você conseguiu conversar com sua família sobre a sua } \\
\text { doença? }\end{array}$ & 1 & 2 & 3 & 4 \\
\hline 6 & $\begin{array}{l}\text { Você ficou preocupado/a em como sua família vai } \\
\text { reagir à sua doença e ao seu tratamento? }\end{array}$ & 1 & 2 & 3 & 4 \\
\hline 7 & $\begin{array}{l}\text { Você ficou preocupado/a com o futuro das pessoas } \\
\text { que são importantes para você? }\end{array}$ & 1 & 2 & 3 & 4 \\
\hline Item & Durante a última semana: & Nada & Um pouco & Moderadamente & Muito \\
\hline 8 & Você ficou preocupado/a com sua saúde no futuro? & 1 & 2 & 3 & 4 \\
\hline 9 & Você teve medo do que pode acontecer no futuro? & 1 & 2 & 3 & 4 \\
\hline 10 & $\begin{array}{l}\text { Você ficou preocupado/a com o que pode acontecer } \\
\text { no final da sua vida? }\end{array}$ & 1 & 2 & 3 & 4 \\
\hline 11 & $\begin{array}{l}\text { Você teve uma visão positiva sobre a vida na semana } \\
\text { passada? }\end{array}$ & 1 & 2 & 3 & 4 \\
\hline 12 & Você teve vontade de fazer as coisas que você gosta? & 1 & 2 & 3 & 4 \\
\hline 13 & O quanto a sua doença foi um peso para você? & 1 & 2 & 3 & 4 \\
\hline 14 & O quanto o seu tratamento foi um peso para você? & 1 & 2 & 3 & 4 \\
\hline
\end{tabular}

\section{DISCUSSION}

The importance and impact of cancer on older people have been widely emphasized in scientific publications, and in the last two decades quality of life has become a fundamental issue in cancer treatment ${ }^{17,18}$. The lack of research studies, however, is represents a lack of proper attention to cancer among older populations ${ }^{18}$.

Quality of life has been a focus of interest in scientific research in recent years, especially regarding older people with chronic diseases. A 
significant number of scales and questionnaires aiming at evaluating quality of life have been developed and used. There are general instruments, appropriate for assessing a number of health problems, and specific instruments, designed to evaluate aspects that are exclusive to selected diseases and/or treatments ${ }^{19,20}$.

Furthermore, health-related quality of life assessment is as important as routine clinical evaluation ${ }^{21}$. Older cancer patients are often treated with non-curative intent and may be vulnerable to the toxic side effects of treatment ${ }^{19}$. Quality of life assessment is helpful in adequately balancing treatment benefits and side effects, providing the instrument used in the evaluation is valid and reliable $e^{13,19}$.

Some studies have already investigated quality of life evaluation among this specific population. Wedding et al. ${ }^{19}$ offers a brief review, concluding that many studies about older people with cancer have used questionnaires not specifically designed for this population, resulting in possible bias in their findings.

The use of quality of life instruments in older people with cancer is not usually preceded by a conceptual evaluation of the relevance of the domains assessed in this population. Some issues remain a challenge, such as the underrepresentation of older people in clinical trials, the proper validation of quality of life instruments, the use of these instruments in methodologically rigorous research, and the homogeneous definitions of at what age people are considered "older"

Some studies suggest the use of a more specific tool, the Comprehensive Geriatric Assessment (CGA), to estimate life expectancy, tolerance to treatment and the identification of factors that potentially interfere with cancer treatment, such as depression, malnutrition, anemia, neutropenia and a lack of support to caregivers, all of which potentially diminish quality of life in this population ${ }^{6,17,21,22}$.

Di Maio and Perrone ${ }^{23}$ state that good quality of life should be a primary goal in cancer treatment, but that this assessment may be hindered by illiteracy, lower resilience, limited acceptance of the questionnaires used, comorbidities and the use of non-validated instruments among the older population.
Thus, the present study describes the first step in the cross-cultural adaptation of the EORTC QLQ-ELD14 to Brazilian Portuguese. We identified the characteristics of the study population, especially those related to the quality of life of older people with cancer, which is the purpose of the study.

Some difficulties were experienced during the study, most of which related to the characteristics of the study population. The original instrument ${ }^{14}$ was self-applied by the respondents but in the population of the present study, medical and schooling characteristics were an obstacle to the self-completion of the questionnaire. We concluded that this instrument should be used in an interview format in Brazilian patients. Despite this, the study was well accepted by the respondents, which allowed the investigation to be performed in accordance with EORTC guidelines. It is important to emphasize that, regarding the manner of use of the questionnaire, the EORTC does not determine values for the evaluation of quality of life as adequate or inadequate. It is recommended, however, that the instrument is used longitudinally, so that, despite the lack of a cut-off point, it is possible to evaluate the evolution of the quality of life of patients.

One limitation of the study is that the field of research was a reference institute, the population of which does not correspond to the general population. However, considering the diversity of patients, it is possible to say that the sample does correspond to the target population of the questionnaire, precisely because it is a reference institute. Moreover, it is worth remembering that the main concern of studies of semantic equivalence is internal validity, that is, the consistency of the findings in the investigated group. Thus, the undertaking of the study in an institute that does not represent the general population (because it provides care to more serious or rare cancer cases than do general hospitals) does not compromise the validity of the study. Thus, the EORTC QLQ-ELD14 instrument adapted to Brazilian Portuguese aims to help professionals by improving the quality of healthcare research and, more specifically, research into the quality of life of older people with cancer. 


\section{CONCLUSION}

It is considered that the present study achieved its established objectives, insofar as the stages of the conceptual equivalence of items and operational semantics were performed, together with the subsequent pre-test for the cross-cultural adaptation of the QLQ-ELD14 instrument to the

The Brazilian version of the EORTC QLQELD14 is promising. Psychometric evaluation of the reliability and validity of this instrument

\section{REFERENCES}

1. Ferlay J, Soerjomataram I, Ervik M, Dikshit R, Eser S, Mathers C, et al. GLOBOCAN 2012 v1.0, Cancer Incidence and Mortality Worldwide: IARC CancerBase No. 11 [Internet]. Lyon: International Agency for Research on Cancer; 2013 [acesso em 16 maio 2015]. Disponível em: http://globocan.iarc

2. BRASIL. Ministério da Saúde, Instituto Nacional de Câncer José Alencar Gomes da Silva, Coordenação de Prevenção e Vigilância. Estimativa 2016: incidência de câncer no Brasil [Internet]. Rio de Janeiro: INCA; 2015 [acesso em 15 dez. 2015]. Disponível em: http://www. inca.gov.br/wcm/dncc/2015/estimativa-2016.asp

3. World Health Organization. Global status report on noncommunicable diseases 2010 [Internet]. Geneva: WHO; 2010. Chapter 1, Burden: mortality, morbidity and risk factors; p. 9-31.

4. Veras R. Population aging today: demands, challenges and innovations. Rev Saúde Pública. 2009;43(3):1-7.

5. Fitzsimmons D, Gilbert J, Howse F, Young T, Arrarras IJ, Brédart A, et al. A Systematic review of the use and validation of health-related quality of life instruments in older cancer patients. Eur J Cancer. 2009;45:19-32.

6. Scher KS, Hurria A. Under-representation of older adults in cancer registration trials: known problem, little progress. J Clin Oncol 2012;30(17): 2036-38.

7. Droz JP, Rodde-Dunet MH, Vitoux A. Développement de l'oncogériatrie :aspects stratégiques nationaux et internationaux. Bull Cancer 2008;95(8):104-7.

8. World Health Organization Quality of Life Group. Development of the Whoqol: Rationale and Current Status. Int J Ment Health. 1994;23(3):24-56.

9. Lowe SS, Watanabe SM, Baracos VE, Courneya KS. Associations between physical activity and Quality of Life in Cancer Patients Receiving Palliative Care: a pilot survey. J Pain Symptom Manage. 2009;38(5):785-96. is currently being performed to complement the cross-cultural adaptation of this questionnaire to Brazilian Portuguese.

Quality of life evaluation is useful as a strong indicator of survival, and for allowing discussion with the patient about issues raised by the questionnaire. This reflection may help multiprofessional healthcare teams to better assess the burden of symptoms and their relative importance, and consequently to better plan and modify treatment strategies.
10. Groenvold M, Klee MC, Sprangers MA, Aaronson NK. Validation of the EORTC QLQC30 quality of life questionnaire through combined qualitative and quantitative assessment of patient-observera. J Clin Epidemiol. 1997;50(4):441-50.

11. Velikova G, Coens C, Efficace F, Greimel E, Groenvold M, Johnson C, et al. Health-related quality of life in EORTC clinical trials - 30 years of progress from methodological developments to making a real impact on oncology practice. EORTC Quality of Life Group and EORTC Quality of Life Department. Eur J Cancer. 2012;1(10):141-9.

12. European Organization for Research and Treatment of Cancer. EORTC Quality of Life Questionnaires. Brussels: EORTC QLQ-C30; 2014.

13. Fontanella BJB, Ricas J, Turato ER. Amostragem por saturação em pesquisas qualitativas em saúde: contribuições teóricas. Cad Saúde Pública. 2008; 24(1):17-27.

14. Wheelwright S, Darlington AS, Fitzsimmons D, Fayers P, Arraras JI, Bonnetain F, et al. International validation of the EORTC QLQ-ELD14 questionnaire for assessment of health-related quality of life elderly patients with cancer. Br J Cancer. 2013;109(4):852-8.

15. Herdman M, Fox-Rushbay J, Badia X. A model of equivalence in the cultural adaptation of HRQoL instruments: the universalist approach. Qual Life Res. 1998;7:323-35.

16. Reichenheim ME, Moraes CL. Operacionalização de adaptação transcultural de instrumentos de aferição usados em epidemiologia. Rev Saúde Pública. 2007;41(4): 665-73.

17. Repetto L, Venturino A, Fratino L, Serraino D, Troisi G, Gianni W, et al. Geriatric Oncology: a clinical approach to the older patient with cancer. Eur J Cancer. 2003;39(7):870-80. 
18. Chen CC, Kenefick AL, Tang ST, McCorkle R. Utilization of comprehensive geriatric assessment in cancer patients. Crit Rev Oncol Hematol. 2004:49(1):53-67.

19. Wedding U, Pientka L, Hoffken K. Quality-of-life in elderly patients with cancer: a short review. Eur J Cancer. 2007;43(15):2203-10.

20. Greenhalgh J. The applications of PROs in clinical practice: what are they, do they work, and why? Qual Life Res. 2009;18(1): 15-3.
21. Balducci L. New paradigms for treating elderly patients with cancer: the comprehensive geriatric assessment and guidelines for supportive care. J Support Oncol. 2003;1(4 Suppl 2):30-7.

22. Balducci L, Colloca G, Cesari M, Gambassi G. Assessment and treatment of elderly patients with cancer. Surg Oncol. 2010;19(3):117-23.

23. Di Maio M, Perrone F. Quality of Life in elderly patients with cancer. Health Qual Life Outcomes. 2003;1:1-9.

Received: August 16, 2016

Revised: January 19, 2017

Accepted: February 15, 2017 